\title{
Staple-line reinforcement using barbed sutures in 1008 sleeve gastrectomies
}

\author{
Görkem Özgen $^{1} \cdot$ İsmail Çalıkoğlu ${ }^{1} \cdot$ Bülent Acunaş $^{2} \cdot$ Mehmet Ali Yerdel $^{1}$ (if \\ Received: 3 February 2021 / Accepted: 28 March 2021 / Published online: 7 April 2021 \\ (C) The Author(s), under exclusive licence to Springer-Verlag GmbH Germany, part of Springer Nature 2021
}

\begin{abstract}
Purpose Among various staple-line reinforcement methods applied during sleeve gastrectomy (SG), although data on fullthickness-continuous-suturing (FTCS) is nearly nil, it has been considered as potentially harmful. The safety/efficacy profile of FTCS is assessed.

Methods All consecutive SGs completing 3-month follow-up were studied. Data on peri-operative parameters, complications, and follow-up were prospectively recorded. All reinforcements were completed by FTCS utilizing barbed suture. Super-super obese, secondary SGs, SGs performed in patients with prior anti-reflux surgery, and SGs performed with additional concomitant procedures were evaluated as "technically demanding" SGs. Student's $t$ /chi-square tests were used as appropriate.

Results Between January 2012 and July 2020, 1008 SGs (941 “primary-standard,” 67 “technically demanding”) were performed without mortality/venous event. Single leak occurred in a patient with sleeve obstruction $(0.1 \%)$. Thirteen bleedings, 4 requiring re-surgery $(0.4 \%)$, and 17 stenoses $(1.7 \%)$ were encountered. Four stenoses were treated with gastric bypass ( 1 emergency), 6 by dilatation(s), and one required parenteral nutrition. Six patients with stenosis chose not to have any treatment. No statistically significant difference was observed in postoperative complications between "primary-standard" and "technically demanding" SGs $(p>0.05)$. The median follow-up was 44 months. The excess weight loss $\%$ at 5 th year was $80.1 \%$. Suturing added $28.4 \pm 6$ minutes to the SG, 3 or fewer sutures were used to complete the reinforcement in $>95 \%$. No mishap/complication occurred related to suturing.

Conclusion FTCS produced excellent result in terms of leakage/hemorrhage with an acceptable stenosis rate at a low cost with half-an-hour increase in the operating time. In contrast to previous allegations, no harm attributable to stitching itself occurred.
\end{abstract}

Keywords Staple-line reinforcement $\cdot$ Sleeve gastrectomy $\cdot$ Over-sewing $\cdot$ Full-thickness suturing $\cdot$ Complications

\section{Introduction}

No standard reinforcement technique is widely accepted as gold-standard when dealing with the long staple-line during sleeve gastrectomy (SG) [1-15]. Different techniques, buttressing, over-sewing, and clip/sealant applications, have been used, sometimes together, with varying degrees of success rates [1]. As stated by Barreto et al. [2], the term "over-

Mehmet Ali Yerdel

yerdel@yerdel.com

1 İstanbul Bariatrics, Obesity and Advanced Laparoscopy Center, Hakkı Yeten Cad, Yeșil Çimen Sok, Polat Tower, No:12/407, Șişli, 34394 İstanbul, Turkey

2 Department of Radiology, Faculty of Medicine, İstanbul University, Çapa, İstanbul, Turkey sewing" traditionally refers to two distinct types of continuous suturing: through and through, full-thickness-continuoussuturing (FTCS) of the staple line, the so-called baseball-suturing is one type; and imbrication of the staple-line by placing sero-muscular bites on either side of the staple-line is the other. Imbrication is the currently preferred over-sewing method worldwide [2-9], based on a debatable hypothesis of the harmful effects of FTCS [10, 11]. Several authors have mentioned the theoretical dangers of FTCS [2, 12-14], but no clear evidence is present. Only a single article provided comparative data on FTCS with barbed suture as a staple-line enforcement method following SG [15]. This revealed no increase in complications.

In this report, data on the safety/efficacy of FTCS of the staple-line by barbed suture in 1008 consecutive SGs are provided. To our knowledge, as a reinforcement technique, this is the largest experience on FTCS reported up to date. 
Furthermore, technical and ergonomic improvements over time, with special emphasis when using barbed suture for FTCS, are addressed.

\section{Material and methods}

The study was approved by the institutional ethics committee and written informed consent was obtained from all participants for both surgery and for the use their data anonymously.

\section{Inclusion criteria}

All consecutive SGs who completed at least 3-month followup were included. Secondary SGs done with re-do bariatric intent, patients who had a prior anti-reflux operation, cases in whom a fundoplication was combined with SG, cases where giant para-esophageal hernias (PEH) were repaired concomitantly with SG and patients with super-super obesity (body mass index $(B M I)>60 \mathrm{~kg} / \mathrm{m}^{2}$ ) were evaluated as "technically demanding" cases.

Our protocols on bougie type/size/usage [16], preoperative workout/SG technique which are the same for all BMIs [17], and just recently, virus related changes during the Covid-19 pandemic have been reported [18]. A low pneumoperitoneum strategy which was continued during the pandemic [18] was already in place (Table 1). Technical differences in patients who have had a prior anti-reflux operation [19] and those undergoing concomitant giant PEH repair have also been reported with video footage [20] . Table 1 summarizes technical changes that we adapted during our entire practice. For the prevention of venous thromboembolism (VTE), all patients received low molecular weight heparin (LMWH) by pre-operative subcutaneous injection according to BMI (BMI $>50$ received $60 \mathrm{mg}$, BMI $<50$ received $40 \mathrm{mg}$ of enoxaparin sodium, repeated every $24 \mathrm{~h}$, for 10 days) (Clexane, pre-filled syringe, Sanofi, Turkey). Patients who were already on oral or novel anti-coagulants were managed by bridging with LMWH and weaning off other anti-coagulation. Pneumatic stocking usage during surgery/hospitalization and early mobilization were routine. In patients with a VTE history, hypercoagulability and with any condition that may prolong immobility, LMWH use was extended individually.

All SGs were performed by the senior author (M.A.Y.) or partly by the surgical staff under his direct supervision. SGs were done routinely over a bougie starting a few centimeters away from the pylorus. Leak test was selective. All patients were drained with a 7-mm Jackson Pratt drain, removed on the third postoperative day after the total output was recorded. In terms of reinforcement, all SGs were completed with the same material/technique.

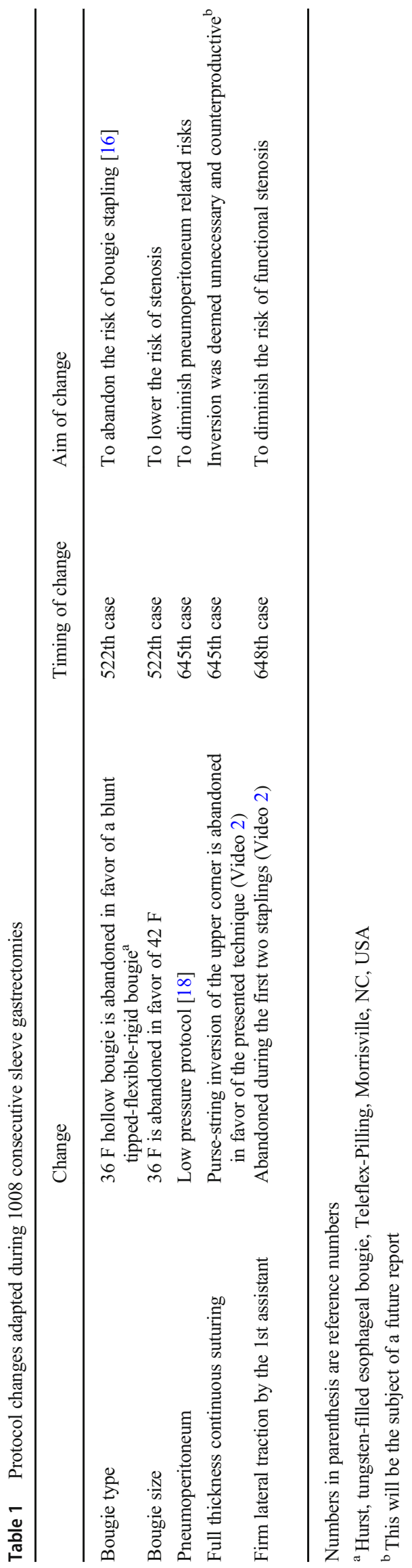




\section{Reinforcement technique}

After the bougie was withdrawn, starting from the upper corner, entirety of the staple-line is continuously sutured by a $6 "$ $(15 \mathrm{~cm}), 000$, barbed suture (V-Loc 180; Medtronic, Minneapolis, MN, USA). All bites were meticulously placed 4-6 $\mathrm{mm}$ apart, from just beneath the staple line, in a fullthickness, through and through manner (Video 1). Upon needle clearance from the tissue, each suture was carefully snugged down with special care to avoid thread misplacement and "locked" tightly. No gap between consecutive sutures was allowed and in time, subsequent sutures overlapped the end of previous one at least $1 \mathrm{~cm}$ in order to secure that all staple-line was adequately addressed (Video 2). First knot cannot be trusted since the suture thread is not "barbed" in close vicinity to the hole. Ergonomic refinements in our technique with increasing experience are addressed in Video 2 and major protocol changes are summarized in Table 1. Upon completion of suturing and forceful washout and irrigation of the staple-line, any further bleeding was addressed by re-stitching with the same material/technique (Video 3). Clips were used rarely as a definitive hemostatic method. In situations when an arterial bleeder became apparent upon the opening of the stapler mouth, clips were still used. Most such clips were removed once the FTCS addressed that segment. No glue/sealant was ever used. The same material/technique was used for the repair of serosal tears and staple misfires (Video 4) as well as the staple-line bleedings requiring re-surgery (Video 3 ). Four defects related to the freeing of 3 inadvertently stapled nasogastric tubes in three patients were also repaired utilizing the same suturing material/technique and video footage has been recently reported [16].

Postoperative day 1 upper GI series was routine. All patients were discharged on the third postoperative day unless there was a complication. During the pandemic, early discharge was encouraged [18].

\section{Definitions}

Leak was defined as the presence of extra-gastric contrast material in tomography [21].

Bleeding was defined as hemorrhage requiring surgery or transfusion. High drain output consistent with a hemoglobin drop managed without transfusion/surgery was also recorded as bleeding.

Stenosis was defined as acute (i.e., inability to start oral liquids, nausea, vomiting) or chronic complaints (i.e., intolerance to solids, frequent vomiting, increased reflux complaints, low weight, malnutrition) in the presence of findings at contrast swallow studies and gastroscopy. Any stenotic segment at upper GI contrast study that is gastroscopically traversable was labeled as functional stenosis (FS). All gastroscopies were done by the senior author (M.A.Y.). In addition to patients who required an intervention due to FS (i.e., central vein catheterization, dilatation, re-surgery), those who had a confirmed FS but declined treatment were also recorded as "sweet" stenosis. In our practice, excluding emergencies, first-line therapy for FS was to do sequential pneumatic balloon dilatations repeated on a maximum of 3 occasions, increasing the diameter and inflation duration; all performed by B.A. as the interventional radiologist and M.A.Y. as the endoscopist. Surgery was reserved only for those with an emergency need or when the dilatation(s) did not work.

Weight loss data is presented as percent excess weight loss (\%EWL). Patients were followed up at 3rd and 6th months, 1 year after surgery and yearly thereafter. Patients who were unable to attend follow-up were reached by phone/video calls to record their weight and stenosis related symptoms.

Data on demographics, duration of surgery (minutes), length of stay (days), the total number of barbed sutures required to suture the entirety of the staple-line per patient, total drain output (milliliters), intra-operative problems (i.e., trocar insertion complications, $\mathrm{CO}_{2}$ emboli, staple misfirings, serosal tears, orogastric tube entrapments), blood product use, early/late complications, and outcome/follow-up parameters were retrieved from our prospectively updated database.

The time (minutes) required to complete the staple-line suturing was measured for the last 400 cases utilizing the video recordings.

\section{Statistics}

Statistical analysis was performed using SPSS software, version 23 (IBM Corp., Armonk, NY, USA). Categorical and numeric parameters were assessed using chi-square and Student $t$-tests, respectively. $P$ values $<0.05$ were regarded as significant.

\section{Results}

Between January 2012 and July 2020, 1008 consecutive patients underwent SG with a minimum of 3-month follow-up. Nine hundred and forty-one patients had a "primary-standard" SG and 67 were regarded as "technically demanding" either due to a secondary/nonstandard bariatric procedure $(n: 40)$ or because they were super-super obese $(n$ : 27). (i.e., 17 were done in patients with concurrent $(n: 10)$ or previous lap/open bands ( $n$ : 7) including one with concomitant plication; 1 was a re-sleeve; 1 was done in a patient with previous endo-stitching with Apollo system; 15 were done in patients who had a prior anti-reflux procedure [19]; 3 were done concomitantly with a partial fundoplication; 3 were done concomitantly with giant PEH repair including a patient with intra-thoracic stomach [20]; 27 had BMI $>60 \mathrm{~kg} / \mathrm{m}^{2}$ ). Demographics and weight data are summarized in Table 2. 
Table 2 Demographics and baseline data

\begin{tabular}{|c|c|c|c|c|}
\hline & Total & $\begin{array}{l}\text { Standard-primary } \\
\text { sleeve gastrectomies }\end{array}$ & $\begin{array}{l}\text { Technically demanding } \\
\text { sleeve gastrectomies }\end{array}$ & $P$ \\
\hline$n$ & 1008 & 941 & 67 & \\
\hline Age (years) & $37.4 \pm 11.0$ & $37.2 \pm 11.1$ & $40.9 \pm 9.9$ & 0.01 \\
\hline $\operatorname{Sex}(\mathrm{F} / \mathrm{M})$ & $614 / 394$ & $575 / 367$ & $40 / 27$ & 0.80 \\
\hline $\begin{array}{l}\text { Body mass index }\left(\mathrm{kg} / \mathrm{m}^{2}\right) \\
\text { (range) }\end{array}$ & $\begin{array}{l}42.1 \pm 7.3 \\
(28.0-74.2)\end{array}$ & $\begin{array}{l}41.7 \pm 6.2 \\
(28-59.8)\end{array}$ & $\begin{array}{l}49.7 \pm 12.9 \\
(28-74.2)\end{array}$ & 0.15 \\
\hline
\end{tabular}

Data on duration of surgery, length of stay, number of sutures per patient, total drain output, and intra-operative problems are summarized in Table 3. Except for an increase in duration of surgery, trocar injuries, total drain output, and $\mathrm{CO}_{2}$ emboli, the remaining parameters were distributed evenly in primary-standard and technically demanding SGs (Table 3). Two trocar injuries affected the colon and all others were liver lacerations. The left colonic injury was a sealed perforation and was managed conservatively as recently reported [17]. The other colonic injury was a serosal tear of the transverse colon and managed by suturing. $\mathrm{CO}_{2}$ emboli occurred in two patients with deep liver lacerations due to trocar injuries and were managed intra-operatively without any sequela.

No mortality occurred. One open conversion was required in a patient with previous open band insertion-extraction operations, both done elsewhere. Upon confronting a large mass in "bursa omentalis," open conversion was required and a "retained" foreign body which was identified as surgical towel was successfully removed. No further sequelae occurred in this patient and the staple-line was sutured openly, with the same material/technique. Distribution of post-operative complications were not statistically different in primary-standard and technically demanding SGs (Table 4). No VTE, including mesenteric vein thrombosis became clinically evident.
The single leak occurred in a super-super obese patient who had a complete obstruction due to a twisted sleeve. He required emergency surgical conversion to a Roux-en-Y gastric bypass for the combined treatment of the leak/stenosis on the 9th postoperative day. This novel approach avoiding the use of stents has been published [21].

Bleeding requiring re-surgery occurred in 4 patients. In one patient, the bleeding was from the splenic hilum and was managed by emergency open surgery 1 day after SG without sequelae. Three were from the staple-line: 2 intra-abdominal, 1 intra-luminal. Two intra-abdominal bleedings from the staple-line were addressed with re-laparoscopy and stitching using the same material/technique (Video 3). The intraluminal bleeding was managed by a novel approach as recently video-reported [22]. Under gastroscopic guidance, the same material/technique was used re-laparoscopically. Among 9 patients with non-surgically treated bleedings, 2 were thought to result from the right trocar site since ultrasound revealed a hematoma at the right upper quadrant. The third was a subcapsular splenic hematoma which was managed conservatively with success. The site of bleeding remained unknown in 6 .

The average time required to complete continuous suturing was $28.4 \pm 6 \min$ (min: 14, $\max : 49$ ). Three or fewer separate sutures were used in more than $95 \%$ of the patients during the

Table 3 Peri-operative data and intra-operative complications

\begin{tabular}{|c|c|c|c|c|}
\hline & Total & $\begin{array}{l}\text { Standard-primary } \\
\text { sleeve gastrectomies }\end{array}$ & $\begin{array}{l}\text { Technically demanding } \\
\text { sleeve gastrectomies }\end{array}$ & $P$ \\
\hline$n$ & 1008 & 941 & 67 & \\
\hline Duration of surgery (minutes) & $102.1 \pm 22.1$ & $100.4 \pm 19.0$ & $130.1 \pm 39.1$ & 0.01 \\
\hline Length of stay (days) & $3.1 \pm 0.9$ & $3.1 \pm 0.4$ & $3.7 \pm 0.6$ & 0.26 \\
\hline Number of barbed suture used per patient & $\begin{array}{l}2.9 \pm 0.4 \\
\text { (range 2-4) }\end{array}$ & $2.9 \pm 0.4$ & 3 & 0.41 \\
\hline Total drain output (milliliters) & $150.1 \pm 95.9$ & $148.3 \pm 83.4$ & $185.2 \pm 144.8$ & 0.01 \\
\hline Stapler misfire $n(\%)$ & $5(0.5)$ & $5(0.5)$ & 0 & 1 \\
\hline Staple-line serosal opening $n(\%)$ & $39(3.9)$ & $36(3.8)$ & $3(4.5)$ & 0.73 \\
\hline Staple-line $\mathrm{NGT}^{\mathrm{a}}$ entrapment $n(\%)$ & $3(0.3)$ & $3(0.3)$ & 0 & 1 \\
\hline Trocar injury $n(\%)$ & $13(1.4)$ & $10(1.0)$ & $3(4.5)$ & 0.01 \\
\hline $\mathrm{CO}_{2}$ emboli $n(\%)$ & $2(0.2)$ & $1(0.1)$ & $1(1.5)$ & 0.01 \\
\hline
\end{tabular}

${ }^{\text {a Nasogastric tube }}$ 
Table 4 Data on complications

\begin{tabular}{|c|c|c|c|c|}
\hline & Total & $\begin{array}{l}\text { Standard-primary } \\
\text { sleeve gastrectomies }\end{array}$ & $\begin{array}{l}\text { Technically demanding } \\
\text { sleeve gastrectomies }\end{array}$ & $P$ \\
\hline$n$ & 1008 & 941 & 67 & \\
\hline Open conversion $n(\%)$ & $1(0.1)$ & 0 & 1 & 1 \\
\hline Bleeding requiring re-surgery $n(\%)$ & $4(0.4)$ & 4 & 0 & \\
\hline Bleeding requiring transfusion $n(\%)$ & $8(0.8)$ & 7 & 1 & \\
\hline Bleeding by hemoglobin drop $n(\%)$ & $1(0.1)$ & 1 & 0 & \\
\hline Total bleeding $n(\%)$ & $13(1.3)$ & 12 & 1 & 0.22 \\
\hline Stenosis requiring emergency surgery $n(\%)$ & $1(0.1)$ & 0 & 1 & \\
\hline Stenosis treated successfully with dilatation $n(\%)$ & $6(0.6)$ & 5 & 1 & \\
\hline Stenosis treated with gastric bypass $n(\%)$ & $3(0.3)$ & 3 & 0 & \\
\hline Stenosis requiring total parenteral nutrition $n(\%)$ & $1(0.1)$ & 1 & 0 & \\
\hline Sweet stenosis $n(\%)$ & $6(0.6)$ & 6 & 0 & \\
\hline Total stenosis $n(\%)$ & $17(1.7)$ & $15(1.6)$ & $2(3.0)$ & 0.32 \\
\hline Leak $n(\%)$ & $1(0.1)$ & $1(0.1)$ & 0 & 0.06 \\
\hline Venous thromboembolism $n(\%)$ & 0 & 0 & 0 & 1 \\
\hline Pneumonia $n(\%)$ & $6(0.5)$ & $6(0.5)$ & 0 & 0.40 \\
\hline Drop foot $n(\%)$ & $5(0.5)$ & $4(0.4)$ & $1(2.5)$ & 0.21 \\
\hline Wound infection $n(\%)$ & $8(0.8)$ & $8(0.8)$ & 0 & 0.46 \\
\hline Rehospitalization $n(\%)$ & $6(0.6)$ & $6(0.6)$ & 0 & 0.52 \\
\hline Mortality $n(\%)$ & 0 & 0 & 0 & 1 \\
\hline
\end{tabular}

entire series. The cost of one barbed suture was 20 USD at the time of writing this article.

During the entire follow-up, including the leak case, 17 patients $(1.7 \%)$ were diagnosed as having an FS. Four FSs were diagnosed prior to discharge, another one on day 10 and ten were diagnosed between 4 and 18 months following the SG. The remaining two FSs were diagnosed at 2 nd and 4th year. All FSs were at the classical mid-gastric portion, except one which occurred at the gastro-esophageal junction. Eleven underwent interventions (Table 4).

Patients were followed up between 3 and 97 months (median follow-up: 44 months). Although no patient was lost to follow-up at 3rd and 6th months, at 1st, 3rd, and 5th year follow-ups, 29 of 944 (drop-out \% = 3\%), 112 of 647 (dropout $\%=17.3 \%$ ), and 136 of 392 (drop-out $\%=34.7 \%$ ) patients were lost to follow-up, respectively. The EWL\% at 1, 3 and 5 years were $90.8 \pm 26.5 \%, 82.7 \pm 24.5 \%$ and $80.1 \pm 26.4 \%$, respectively. In patients who did not complete the third month follow-up, no leak, bleeding, VTE, or stenosis was diagnosed.

\section{Discussion}

SG is becoming the most popular primary bariatric procedure worldwide. There is little doubt that the staple-line, which is the longest in any given abdominal procedure, has to be reinforced [1, 23-25]. SG has 4 major complications: leakage, bleeding, stenosis, and VTE. The optimum reinforcement technique should result minimal rates of leak and bleeding and must not put the patient under increased risk for VTE and stenosis.

In our experience, FTCS of the staple-line achieved less than $0.1 \%$ leak and $0.4 \%$ surgical bleeding rates without any VTE in 1008 consecutive SGs. Technically demanding SG patients had no statistically different rate for post-operative complications. Leak, the most feared complication of SG, occurred only in one patient who developed a completely obstructed sleeve, a known risk factor for leak. The $0.1 \%$ leak rate was therefore remarkable and is lower than the minimum range of all reported evidence from previous meta-analyses [23-25] and systematic reviews [1, 26]. Hypothetically, the second continuous layer with FTCS, by providing higher bursting pressure, might have had a protective effect. Apparently, in almost 1000 consecutive SGs, we had zero leak rate in patients without stenosis.

Notably, only 3 staple-line bleedings were diagnosed. Even if we assume all 6 bleedings with unknown source were also from the staple-line, a $0.9 \%$ rate of staple-line bleeding is comparable with other reports [1, 23-25].

Since continuous suturing can narrow the sleeve further, it may be reasonable to assume that the stenosis rates might be higher with this practice. Several authors [5, 9] reported increased stenosis by imbrication suturing and Cottam et al. mentioned 5 cases of stenosis that they attributed to oversewing [3]. However, suturing was not associated with higher stenosis rate in other reports $[6,15]$. We must emphasize that 
the "tolerable" stenoses were also included in our analysis. Such patients, as long as they do not get severely malnourished, are reluctant to have an intervention because of the fear of weight regain. These tolerable stenoses are frequently underreported but were not excluded herein. Therefore, our $1.7 \%$ FS rate is actually comparable to the reported rates in series using different reinforcement techniques where extended terms of follow-up is employed, specifically scrutinizing on FSs. Importantly, by technical refinements such as no lateral traction during the first 2 staplings and extreme caution to avoid a twist across the staple-line, no new FS was diagnosed in 360 patients during the last 2.5 years. In contrast, after a similar follow-up, we had observed $2.4 \%$ FS rate in our initial $337 \mathrm{SG}$ patients [21]. It is possible that an FS mainly occurs due to errors in stapling rather than suturing. Most commonly, "too-tight" stapling across the "incisura angularis" (which is mainly the function of left lateral traction) or the twisting of an un-evenly stapled sleeve, especially if effects the mid-gastric portion, leads to stenosis. Suturing may have a secondary effect, if not done meticulously (i.e., taking very large bites or bites that are too far apart). The single proximal stenosis case which required dilatation was thought to have resulted from the practice of purse string inversion of the upper corner. This practice was abandoned later (Table 1).

In contrast to imbrication suturing, buttressing methods, or any clips/sealants, FTCS, by nature, provides a water-tight secondary layer as mentioned above and addresses all probable staple-line misadventures even though some may not even come to attention intra-operatively. This may well be another reason for the low leak rate achieved with the presented technique. No bariatric re-do is easy and all are technically demanding. Cases having had a previous band or undergoing a band removal concomitantly with SG, patients who had previous anti-reflux surgery, or a prior sleeve may be more prone to staple-line complications because of adhesions, scar tissue, distorted anatomy, or presence of staples/clips. The technique presented herein, therefore, may be even more useful in such patients.

The results achieved herein may not be reproduced in inexperienced hands and this may be regarded as a potential weakness of the study. However, suturing the staple-line of an SG is relatively easy provided that reasonable intracorporeal suturing experience is available, a basic requirement in bariatric practice. Although this study cannot provide data on a learning curve since the duration of suturing was measured only in the last 400 cases, entire suturing added less than 30 min to surgical time. Reports on over-sewing by imbrication $[2,4,9,14]$ or by FTCS [15] showed an increase in the operating time, similar to herein. The cephalo-caudally oriented vertical staple-line is located just across the camera residing between the both hands of the surgeon. With proper monitor placement, excellent optical correctness is readily available, allowing great comfort to either a left or a right-handed surgeon. Therefore, the presented technique, unlike many handsewn anastomoses in difficult locations, is reproducible and no extreme skill is necessary. Importantly, in contrast to the previous hypothesis [10] and theoretical concerns [2, 11-14] on the potentially tearing and thereby harmful effect of FTCS, not even a single mishap/complication related to suturing itself occurred during our entire practice.

Barbed sutures are being increasingly used during various operations, including bariatric procedures [15, 27]. Some are routinely using them when closing staple openings or mesenteric defects and staple-line reinforcement by continuous "imbrication" with a barbed suture has already produced good results in comparison to no-reinforcement [14]. Several points deserve emphasis when using barbed sutures. First, it is unidirectional and once the needle is cleared from the tissue, the thread cannot and should not be pulled back. For this reason, each bite must be meticulously taken and each suture must be very carefully snugged down to a proper position without any displacement since once the locking occurs, there will not be another chance to adjust. This detail is especially important during the first lock, using the "hole," when performing the initial knot. Care needs to be taken with the first knot since the suture is not barbed nearby the hole. Unless the first knot is a thick bite, you will only be able to lock it after the second bite. Second, each subsequent suture must overlap the previous one at by least $1 \mathrm{~cm}$ to avoid any unaddressed segment. Some bleedings in our series may have resulted from such technical failures. It is noteworthy however that thousands of individual sutures were used, but we never encountered even a single episode of suture snapping, although the suture was held firmly by a needle holder at similar spots repeatedly and pulled strongly when snugging down. Preferring the $15 \mathrm{~cm}$ in length product instead of longer ones allows best ergonomics for perpetual suturing as addressed in Video 2.

No use of any buttress material or any other hemostatic product and fewer clip usage are factors making the presented technique considerably cheaper than most other reinforcement methods. The additional cost per patient is around 60 USDs, making this around 10 times cheaper than some popular buttressing alternatives [4, 28]. Duration of surgery has negligible impact on the overall cost in our country. It should be noted however, in centers where theater cost is calculated by minutes, cost savings may be less significant. Furthermore, the technique presented herein gives the surgeon an opportunity to do size re-adjustments of the sleeve, by taking thicker bites in order to diminish the diameter of the sleeve. Special care is required to avoid this practice around the mid-gastric portion to avoid FS.

A major weakness of our study is that it does not provide comparative data. Therefore, we can only speculate when making any comparison with other methods. Other reinforcing methods may well be equally satisfactory and a definitive comparison can only be made by a randomized trial. Another 
weakness is that we might have underdiagnosed some VTEs as no routine imaging was done, which would have been unethical, in asymptomatic patients. Similarly, we accept the fact that our stenosis rate reflects a minimum because of midterm lost to follow-ups. A few stenoses might have remained undiagnosed. However, our report describes prospectively recorded complications in a large consecutive series of SGs without exclusions that were performed and followed up by the same team, under a protocol. It dispels the notion that reinforcement of a gastric staple line by FTCS is risky.

\section{Conclusion}

Meticulous, FTCS of the staple-line utilizing barbed suture produced excellent results in terms of leakage, the most devastating complication of SG, with a very low cost. The technique was also effective in achieving bleeding and stenosis rates comparable to previous reports. Importantly, in contradiction to previous allegations, no evidence of harm was observed attributable to stitching itself.

Supplementary Information The online version contains supplementary material available at https://doi.org/10.1007/s00423-021-02161-5.

Acknowledgements Authors thank to Murat Akyol M.D., F.R.C.S. and Sadettin Karacagil M.D., Ph.D for reviewing the article.

Authors' contributions Authorship M.A. Y and B. A participated in study conception and design and critical revision of manuscript; G. Ö and $\dot{I}$. Ç participated in acquisition of data, analysis and interpretation of data, and drafting of manuscript.

Data availability Data on 1008 cases is uploaded to Synapse.org. Links: https://www.synapse.org/\#!Synapse:syn24241492 and https://www. synapse.org/\#!Synapse:syn24241491.

Code availability Not applicable.

\section{Declarations}

Ethics approval The study is approved by the institutional ethics committee.

Consent to participate Written informed consent is obtained from all participating patients. Participants also consented for the usage of data anonymously.

Competing interests The authors declare no competing interests.

\section{References}

1. Gagner M, Kemmeter P (2020) Comparison of laparoscopic sleeve gastrectomy leak rates in five staple-line reinforcement options: a systematic review. Surg Endosc 34:396-407
2. Barreto TW, Kemmeter PR, Paletta MP, Davis AT (2015) A comparison of a single center's experience with three staple line reinforcement techniques in 1,502 laparoscopic sleeve gastrectomy patients. Obes Surg 25:418-422

3. Cottam D, Qureshi FG, Mattar SG, Sharma S, Holover S, Bonomani G, Schauer P (2006) Laparoscopic sleeve gastrectomy as an initial weight-loss procedure for high-risk patients with morbid obesity. Surg Endosc 20:859-863

4. Dapri G, Cadiere GB, Himpens J (2011) Laparoscopic repeat sleeve gastrectomy versus duodenal switch after isolated sleeve gastrectomy for obesity. Surg Obes Relat Dis 7:38-43

5. Musella M, Milone M, Bellini M, Leongito M, Guarino R, Milone F (2011) Laparoscopic sleeve gastrectomy. Do we need to oversew the staple line? Ann Ital Chir 82:273-277

6. Gentileschi P, Camperchioli I, D’Ugo S, Benavoli D, Gaspari AL (2012) Staple-line reinforcement during laparoscopic sleeve gastrectomy using three different techniques: a randomized trial. Surg Endosc 26:2623-2629

7. Al Hajj GN, Haddad J (2013) Preventing staple-line leak in sleeve gastrectomy: reinforcement with bovine pericardium vs oversewing. Obes Surg 23:1915-1921

8. D'Ugo S, Gentileschi P, Benavoli D, Cerci M, Gaspari A, Berta RD, Moretto C, Bellini R, Basso N, Casella G, Soricelli E, Cutolo P, Formisano G, Angrisani L, Anselmino M (2014) Comparative use of different techniques for leak and bleeding prevention during laparoscopic sleeve gastrectomy: a multicenter study. Surg Obes Relat Dis 10:450-454

9. Taha O, Abdelaal M, Talaat M, Abozeid M (2018) A randomized comparison between staple-line oversewing versus no reinforcement during laparoscopic vertical sleeve gastrectomy. Obes Surg 28:218-225

10. Baker RS, Foote J, Kemmeter P, Brady R, Vroegop T, Serveld M (2004) The science of stapling and leaks. Obes Surg 14:1290-1298

11. Gagner M (2011) Meta-analysis of leaks following laparoscopic vertical sleeve gastrectomy. Obes Surg 21:958 abstract PL02-05; presented at the XVI World Congress of International Federation of the Surgery of Obesity (IFSO), Aug 31-Sept 3, 2011, Hamburg, Germany

12. Pinheiro JS, Correa JL, Cohen RV, Novaes JA, Schiavon CA (2006) Staple line reinforcement with new biomaterial increased burst strength pressure: an animal study. Surg Obes Relat Dis 2: 397-399

13. Chen B, Kiriakopoulos A, Tsakayannis D, Wachtel MS, Linos D, Frezza EE (2009) Reinforcement does not necessarily reduce the rate of staple line leaks after sleeve gastrectomy. A review of the literature and clinical experiences. Obes Surg 19:166-172

14. Hany M, Ibrahim M (2018) Comparison between staple line reinforcement by barbed suture and non-reinforcement in sleeve gastrectomy: a randomized prospective controlled study. Obes Surg 28:2157-2164

15. Carandina S, Tabbara M, Bossi M, Valenti A, Polliand C, Genser L, Barrat C (2016) Staple line reinforcement during laparoscopic sleeve gastrectomy: absorbable monofilament, barbed suture, fibrin glue, or nothing? Results of a prospective randomized study. J Gastrointest Surg 20:361-366

16. Calıkoğlu İ, Özgen G, Yerdel MA (2021) Inadvertent stapling of the orogastric tube during bariatric surgery. Report of 3 cases and a systematic review. Medicine 100(2):e24144. https://doi.org/10. 1097/MD.0000000000024144

17. Şen O, Çalıkoğlu İ, Özgen G, Türkçapar AG, Yerdel MA (2020) Sleeve gastrectomy in class 1 obesity: assessment of operative outcomes. Surg Obes Relat Dis. https://doi.org/10.1016/j.soard.2020. 08.014 August 26, 2020

18. Yerdel MA, Özgen G (2021) Eightyseven consecutive sleeve gastrectomies between the two peaks of the pandemic. An opening 
phase experience. Obes Surg. https://doi.org/10.1007/s11695-02105339-4

19. Şen O, Çalıkoğlu İ, Özgen G, Toydemir T, Türkçapar AG, Yerdel MA (2019) Sleeve gastrectomy in patients with previous antireflux surgery. Preliminary results of the "no-touch to posterior wrap" technique. Surg Obes Relat Dis 15:1668-1674

20. Yerdel MA, Çalıkoğlu İ, Özgen G (2020) Mesh repair of a giant para-esophageal hernia + sleeve gastrectomy. Combined treatment of intra-thoracic stomach and morbid obesity: a video case presentation. Obes Surg 30:3255-3257

21. Yerdel MA, Türkçapar AG, Roslin MS (2016) Emergency roux-eny gastric bypass to treat "stenosis+leak" combination after sleeve gastrectomy in a super-super obese individual. Surg Obes Relat Dis 12:e350-e357

22. Çalıkoğlu İ, Hamzaoğlu H, Yerdel MA (2020) Combined use of endoscopy to guide laparoscopic management of intraluminal bleeding from the staple-line after sleeve gastrectomy: a video case report. Surg Obes Relat Dis 16:1156-1157

23. Shikora SA, Mahoney CB (2015) Clinical benefit of gastric staple line reinforcement (SLR) in gastrointestinal surgery: a meta-analysis. Obes Surg 25:1133-1141

24. Wu C, Wang FG, Yan WM, Yan M, Song MM (2020) Is there necessity for oversewing the staple line during laparoscopic sleeve gastrectomy? An updated systematic review and meta-analysis of randomized controlled trials. J Investig Surg 33:839-850

25. Choi YY, Bae J, Hur KY, Choi D, Kim YJ (2012) Reinforcing the staple line during laparoscopic sleeve gastrectomy: does it have advantages? A meta-analysis. Obes Surg 22:1206-1213

26. Gagner M, Buchwald JN (2014) Comparison of laparoscopic sleeve gastrectomy leak rates in four staple-line reinforcement options: a systematic review. Surg Obes Relat Dis 10:713-724

27. Lin Y, Long Y, Lai S, Zhang Y, Guo Q, Huang J, Du L (2019) The effectiveness and safety of barbed sutures in the bariatric surgery: a systematic review and meta-analysis. Obes Surg 29:1756-1764

28. Gayrel X, Loureiro M, Skalli EM, Dutot C, Mercier G, Nocca D (2016) Clinical and economic evaluation of absorbable staple line buttressing in sleeve gastrectomy in high-risk patients. Obes Surg 26:1710-1716

Publisher's note Springer Nature remains neutral with regard to jurisdictional claims in published maps and institutional affiliations. 